\title{
FORMAÇÃO DE PROFESSORES DOS ANOS INICIAIS DO ENSINO FUNDAMENTAL PARA A MULTIPLICAÇÃO E DIVISÃO NO SISTEMA ELKONIN-DAVYDOV
}

\author{
ELEMENTARY SCHOOL INICIAL-YEARS-TEACHER'S TRANING FOR USING
}

MULTIPLICATION AND DIVISION BASEDON ELKONIN-DAVYDOV SYSTEM Eloir Fátima Mondardo Cardoso ${ }^{1}$, Lucas Sid Moneretto Búrigo ${ }^{2}$, Gislene Camargo ${ }^{3}$,
Aline Alves das Neves ${ }^{4}$, Isadora da Silva Lemos ${ }^{5}$, Amanda Caroline dos Santos ${ }^{6}$

\begin{abstract}
RESUMO
Os professores de Matemática do sexto ano escolar da rede de ensino municipal de Criciúma localizada no estado brasileiro de Santa Catarina - têm identificado nos estudantes lacunas em relação aos conceitos ensinados nos anos escolares anteriores. Para esses professores, a maioria dos estudantes do início dos anos finais do Ensino Fundamental (EF) apresentam equívocos conceituais em situações relacionadas, principalmente, à multiplicação e à divisão. Nossa hipótese é que esses problemas da não apropriação, pelos estudantes das significações conceituais de Matemática, estão relacionados ao conhecimento empírico adotado para a organização do ensino. Com a finalidade de abolir as lacunas na aprendizagem de Matemática, nos estudantes, desenvolveu-se um projeto de extensão. A questão investigada foi: quais as contribuições de uma formação de professoras dos anos iniciais para reelaborar a organização do ensino de multiplicação e divisão, com base nos fundamentos do sistema de Elkonin-Davydov? Para a análise dos dados foram transcritas as falas das professoras que foram gravadas durante os encontros mensais. A partir das discussões realizadas na formação, as professoras constataram que no sistema de ensino de Elkonin-Davydov a multiplicação e a divisão possuem os mesmos elementos conceituais no contexto da medição de grandezas com base em duas unidades: básica e intermediária, mas com finalidades distintas. Essa constatação supera o modo de ensino fragmentado dessas operações, realizadas por elas, anteriormente a participação no projeto de extensão. Além disso, foi identificadaa relação dos elementos da multiplicação em consonância com os fundamentos da Matemática.
\end{abstract}

Palavras-chave: Sistema de ensino Elkonin-Davydov; Formação de professores; Multiplicação; Divisão.

\footnotetext{
ABSTRACT

Sixth Grade Mathematics teachers of the municipal school system in Criciúma - a Brazilian city in the state of Santa Catarina - have identified gaps in students in relation to the concepts which were taught in previous school years. For these teachers, the majority of students in the

${ }^{1}$ Professora da Universidade do Extremo Sul Catarinense (UNESC). E-mail: efm@unesc.net

${ }^{2}$ Professor da UNESC.

${ }^{3}$ Professora da UNESC.

${ }^{4}$ Egressa do curso de Licenciatura em Matemática da UNESC, bolsista do projeto de extensão.

${ }^{5}$ Egressa do curso de Pedagogia da UNESC, bolsista do projeto de extensão.

${ }^{6}$ Graduanda do curso de Pedagogia da UNESC, bolsista do projeto de extensão.
} 
beginning of the final years of elementary school present conceptual mistakes concerning situations related mainly to multiplication and division. The hypothesis defended by this study is that the problem of students not appropriating the conceptual meanings of Mathematics, are related to the empirical knowledge which were adopted for the organization of teaching. Therefore, in order to eliminate the students` gaps in Mathematics learning, an extension project was developed. Thus, the study investigated the following issue: what are the contributions of training early year teachers to re-elaborate the organization of multiplication and division teaching, based on the fundamentals of the Elkonin-Davydov system? For data analysis, teachers' speeches which were recorded during the monthly meetings were transcribed. From the discussions carried out during the training, teachers verified that according to the Elkonin-Davydov educational system, multiplication and division have the same conceptual elements in the context of measuring quantities based on two units: basic and intermediate, but with different purposes. Such finding overcomes the fragmented teaching method of these operations, used by the teachers, before taking part in the extension project. Moreover, the relationship between the elements of multiplication in accordance with the foundations of mathematics was identified.

Keywords: Elkonin-Davydov Educational System; Teacher Training; Multiplication; Division.

\section{INTRODUÇÃO}

Diversos professores brasileiros de Matemática, têm identificado nos estudantes do sexto ano escolar, lacunas em relação a conceitos matemáticos ensinados nos anos escolares anteriores. Soares (2007) constatouque os estudantes apresentam dificuldades no entendimento da divisão com números naturais durante a primeira fase do Ensino Fundamental e, por consequência, eles recorrem à estratégia de memorização desse conceito, masisso ainda ocasiona dúvidas no processo de resolução de situações sobre a divisão.Essa situação tambémé expressa por professores de Matemática da rede municipal de Criciúma pertencente ao estado de Santa Catarina. Esses professores relataram que um número considerável de estudantes do sexto ano escolar apresentam equívocos conceituais em situações relacionadas, principalmente, a multiplicação e a divisão.

O entendimento da multiplicação e da divisão contribui para a apropriação da Matemática no Ensino Fundamental II, uma vez que os conceitos dessa disciplina estão interrelacionados. Desse modo, a não aprendizagem dessas duas operações no Ensino Fundamental I se constituirá como obstáculo na sequência do ensino. Com base na relevância da multiplicação e da divisão para o Ensino Fundamental II, levantamos os seguintes questionamentos: Com qual finalidade é organizado o ensino dos conceitos matemáticos nos anos iniciais do Ensino Fundamental? Qual a base teórica das propostas curriculares das redes de ensino que orientam os professores na prática pedagógica? Os professores ensinam os 
conceitos de multiplicação e divisão com base na concepção teórica das propostas curriculares?

Davídov (1988) ao estudar os sistemas de ensino da Rússia, identificou que os problemas da não apropriação dos conceitos matemáticos estavam vinculados ao conteúdo e ao método adotado pelo modo de organização de ensino que adere ao desenvolvimento do pensamento empírico. Para Davidov e Márkova (2019, p. 203) “o pensamento empírico está relacionado com um nível de transmissão de conhecimentos, no qual, nas crianças, se formam somente modos particulares e isolados de soluções de tarefas práticas concretas.”. Sendo assim,o estudante recorre aos conhecimentos que foram transmitidos de forma imediata, pelo professor, para a resolução das tarefas.

Para superar os problemas decorrentes do ensino que desenvolve o pensamento empírico, Davídov, Elkonin e colaboradores adotaram outro conteúdo e método para a organização de um sistema de ensino que prioriza o desenvolvimento do pensamento teórico por meio da apropriação do conhecimento científico.

Com base no sistema de ensino de Elkonin-Davydov e colaboradores, que possui o objetivo de promover o desenvolvimento teórico conceitual nos estudantes, foi organizada uma formação continuada em Matemática a partir de um projeto de extensão para professores do quinto ano escolar ${ }^{7}$ da rede municipal de ensino de Criciúma.Essa formação continuada teve por intuito discutir a organização do ensino de Matemática com os pressupostos psicológicos da Teoria Histórico-Cultural. Essa adoção é decorrente da concepção que fundamenta a Proposta Curricular desse município.

A participação das professoras na formação continuada permite reformular o processo de ensino da multiplicação e da divisão no Ensino Fundamental I. Diante disso, surge o problema: Quais as contribuições de uma formação de professoras dos anos iniciais para reelaborar a organização do ensino de multiplicação e divisão, com base nos fundamentos do sistema de Elkonin-Davydov? Por sua vez, o objetivo foi analisar as contribuições investigadas no problema.

A formação continuada foi desenvolvida por meio de encontros ${ }^{8}$ que foram gravados no formato de vídeo e esses materiais fizeram parte da análise dos dados. Foi realizada a transcrição das falas das professoras, nos encontros da formação, que serão identificadas no decorrer da análise e estão entre aspas e em itálico.Dentre as diversas expressões transcritas, o

\footnotetext{
${ }^{7}$ Professores do primeiro ao quinto ano do Colégio UNESC, também participaram desta formação.

${ }^{8}$ Esses encontros ocorreram de forma presencial, uma vez por mês, no período de agosto de 2018 até dezembro de 2019. Participaram desse projeto aproximadamente oitenta professoras.
} 
foco de análise está naquelas falas que remetem às contribuições do estudo do sistema Elkonin-Davydov para repensar a organização do ensino de multiplicação e de divisão.

\section{RESULTADOS E DISCUSSÃO}

No sistema de ensino Elkonin-Davydov, a Matemática é organizada para que os conceitos sejam apropriados a partir das relações entre grandezas, com a justificativa que elas promovem o surgimento dos conceitos matemáticos. É por isso que Davýdov (1982) considera as grandezas como o objeto essencial da Matemática e as denomina como o geral dessa disciplina.

Desse modo, os conceitos matemáticos do sistema de Elkonin-Davydov discutidos de modo articulado na formação foram: grandezas (discretas e contínuas), número, adição, subtração, resolução de problemas, sistema de numeração, multiplicação (tabuada), divisão e fração. Embora a necessidade manifestada pelos professores, para o surgimento dessa formação, se justifica na insuficiência de significados conceituais da multiplicação e da divisão, entendemos que essas operações carregam os significados de conceitos anteriores inter-relacionados desde o primeiro ano escolar. Tais significados se dirigem para a compreensão da relação geneticamente universal do número, isto é, a relação de multiplicidade e de divisibilidade. Esse entendimento envolve a medição da grandeza por meio de uma unidade de medida (ROSA, 2012).

Além dadiscussão de tarefas do sistema Elkonin-Davydov, tambémhouve a introdução de histórias virtuais que são decorrentes da Atividade Orientadora de Ensino (AOE) que traduz os pressupostos da Teoria Histórico-Cultural para o contexto educacional brasileiro (MOURA, 2010).

A AOE para Moura (2010) é materializada por meio de situações desencadeadoras de aprendizagem que podem ser desenvolvidas a partir dos seguintes recursos metodológicos: situações emergentes do cotidiano, jogos infantis e história virtual do conceito.

Esta última é compreendida como uma narrativa que proporciona ao aluno envolverse na solução de um problema como se fosse parte de um coletivo que busca solucioná-lo, tendo como fim a satisfação de uma determinada necessidade à semelhança do que pode ter acontecido em certo momento histórico da humanidade (MOURA et. al, 2010, p. 224). 
A história virtual do conceito fez parte da discussão da organização do ensino para a divisão. Por meio dessa formação, cinco professoras desenvolveram com os seus estudantes a história virtual “A produção de laços de Dona Baratinha” produzida pela Crestani (2016) 9 .

A multiplicação e a divisão no sistema de Elkonin-Davydov possui ênfase para os nexos conceituais no contexto da medição e envolve uma grandeza a ser medida, bem como, as unidades básica e intermediária. Inicialmente propomos uma tarefa que revela a relação essencial da multiplicação. Contudo, ela suscita elementos que inter-relacionam sua conexão com a divisão.

Tarefa1:Precisamos medir o volume C por meioda unidade A.

Figura 1: grandeza $\mathrm{C}$ e unidade de medida $\mathrm{A}$

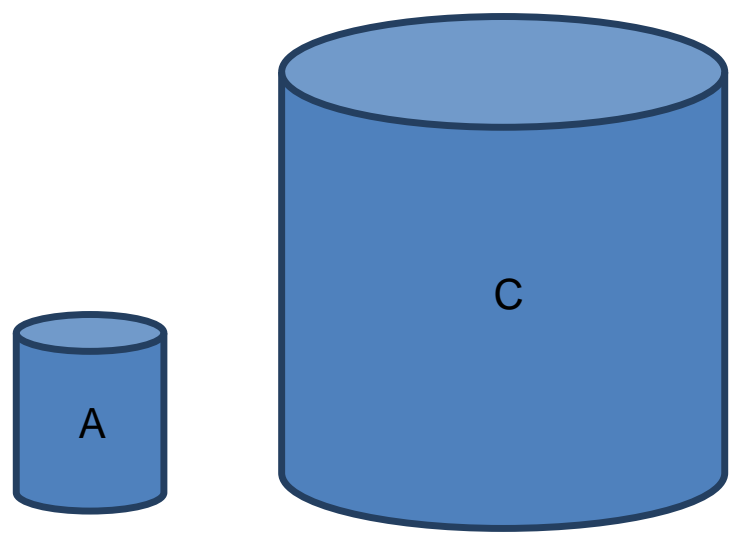

Fonte: Elaboração dos autores

O recipiente $\mathrm{A}$, unidade de medida, tornou o processo de medição do volume do recipiente $\mathrm{C}$ demorado, dada a grande diferença entre os tamanhos das grandezas envolvidas. Sendo assim surge à necessidade de buscar um modo que agilize essa medição. Para isso, é introduzida a unidade de medida intermediária (B), figura 2, que corresponde a três vezes o volume da unidade básica $\mathrm{A}, \mathrm{B}=3 \mathrm{~A}$.

\footnotetext{
${ }^{9}$ História virtual“"A produção de laços de Dona Baratinha” na íntegra (Crestani, 2016, p. 88).
} 
Figura 2: unidade de medida: básica (A) e intermediária (B)

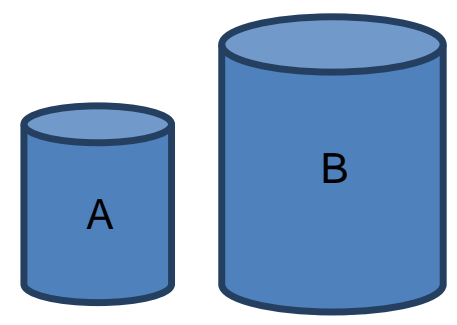

Fonte: Elaboração dos autores

No processo de investigação da medição do volume $\mathrm{C}$, a utilização da unidade $\mathrm{B}$ (intermediária) permitiu calcular o volume $\mathrm{C}$ (total de medidas básicas). Nesse cálculo a unidade $\mathrm{B}$ carrega três unidades básicas e pelo fato de o volume $\mathrm{C}$ conter quatro unidades $\mathrm{B}$, significa que a medida intermediária se repete por quatro vezes $(3 \cdot 4)$. Esse processo de medição está expresso por meio do caráter objetal na figura 3.

Figura 3:Representação da medição da grandeza C a partir das unidades A e B.
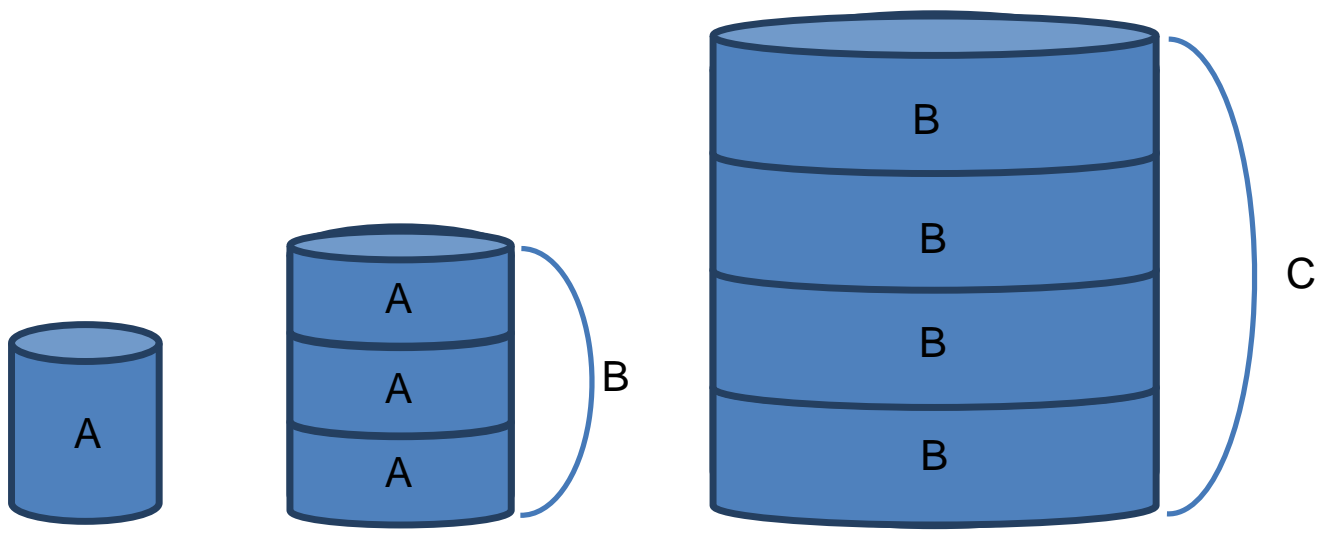

Fonte: Elaboração dos autores

A representação de medição pelo modo objetal (figura 3)éexpressapor meio de ummodelo (figura 4), com a finalidade darepresentação no plano mental dos elementos conceituais da multiplicação, isto é, a unidade intermediária formada por unidades básicas. 
Figura 4: Modelo da multiplicação e da divisão

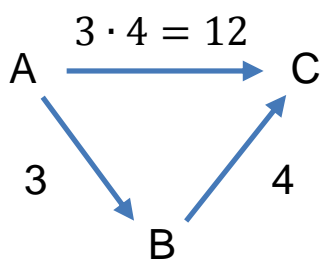

Fonte: Elaboração com base em Crestani (2016)

Esse modelotraduz o movimento de medição do volume $\mathrm{C}$ a partir da unidade básica $\mathrm{A}$ e intermediada pela unidade B que se repete por quatro vezes. No sistema de ensino de Elkonin-Davydov a multiplicação: $a \cdot b$, o número $a$ é o multiplicando e o número $b$ é o multiplicador. De acordo com Caraça (2010) o multiplicador (b) possui o papel ativo e indica quantas vezes será tomado o número $a$, multiplicando: $\overbrace{a+a+\ldots+a}^{b \text { vezes }}=a \cdot b$. A multiplicação $3 \cdot 4$ possui o significado de que o três é tomado por quatro vezes, ou seja, $3+3+3+3$.

A partir da discussão da multiplicação nesse modo de ensino, uma professora expressou que "não é dessa forma que a gente trabalha em que o multiplicador é o segundo fator". A forma de abordar esse conceito para a mesma professora é que o "multiplicador é o primeiro fator". Na multiplicação $3 \cdot 4$ a leitura realizada é três vezes o quatro, em que o três cumpre o papel de multiplicador e o quatro multiplicando. Em outras palavras, a ênfase está na expressão verbal do significado do três, o qual indica quantas vezes o quatro será somado: $3 \cdot 4=4+4+4$.

As falas anteriores da professora revelam o entendimento do ensino de multiplicação, cuja base principal são os livros didáticos brasileiros. Portanto, vale reafirmar que nos fundamentos de matemática em uma concepção dialética materialista, na operação $3 \cdot 4$, o três é o multiplicando e o quatro o multiplicador (CARAÇA, 2010).

Davídov (1987) destaca que o ensino tradicional adere que o conhecimento seja apresentado ao estudante por meio de abstrações verbais claras e sucessivamente separadas. $\mathrm{Na}$ multiplicação, três vezes o quatro $(3 \cdot 4)$, o caráter verbal representa que o quatro é o multiplicando e, o três, o multiplicador. Desse modo, está claro quais são os papeis dos elementos da multiplicação. Após a apresentação da abstração verbal, ela deve ser relacionada pela criança com uma imagem sensorial, isto é, justificar que três vezes o quatro significa ter três grupos de objetos com quatro elementos em cada grupo (DAVÍDOV, 1987). Ressaltamos 
ainda que, a escolha, por exemplos de situações concretas do cotidiano para iniciar o ensino de um conceito remete ao movimento do particular para o geral.

O sistema de Elkonin-Davydov, em contraposição ao ensino com princípios tradicionais, se fundamenta no movimento do geral para o particular na sua organização. A multiplicação no referido sistema de ensino é decorrente de um processo investigativo que permite o estudante identificar a necessidade que remete a essência do conceito. Além disso, a multiplicação é representada em um esquema, e nesse, os elementos da multiplicação estão de acordo com os fundamentos da matemática segundo Caraça (2010).

O estudo da multiplicação por meio da medição de grandezas - conforme apresentado na tarefa anterior - permite ao estudante identificar o multiplicando (medida da unidade intermediária em relação à unidade básica) e o multiplicador (quantidade de vezes que a unidade intermediária se repete na grandeza a ser medida). Essa compreensão dos elementos da multiplicação é utilizada para a introdução da tabuada.

O ensino de tabuada do número quatro manifestado pelas professoras de acordo como desenvolviam esse conceito, antes da formação seguia a manifestação verbal já relatada. Assim sendo, $4 \cdot 1=1+1+1+1,4 \cdot 2=2+2+2+2$ e, assim sucessivamente. Nessa tabuada o número que representa o produto aumenta de quatro em quatro unidades, ao variar uma unidade no multiplicando. No entanto, o número que é somado uma quantidade de vezes, em cada multiplicação, não é o quatro. Enquanto isso, no sistema Elkonin-Davydov a tabuada do quatro $4 \cdot 1=4,4 \cdot 2=4+4,4 \cdot 3=4+4+4$, segue uma sequência em que o quatro representa a medida da unidade intermediária e, por isso, se repete por uma vez, duas vezes, três vezes.

Esse entendimento é manifestado por outra professora ao justificar o procedimento anterior com a fala:

\footnotetext{
"o que a professora fez, ela usou várias unidades de medidas. Quatro vezes um, usou a unidade de medida um. Quatro vezes dois, usou a unidade de medida dois, que foi o que se repetiu. Na verdade, pelo princípio davydoviano, a unidade de medida é inicial, é princípio. É ela que vai se repetir na tabuada, na sequência. Na tabuada do quatro, a unidade de medida é sempre quatro. O princípio é a constância na unidade de medida".
}

Essa fala representa a diferença entre os dois modos de ensinar a tabuada. Enquanto no sistema de Elkonin-Davydov existem agrupamentos com a mesma medida, no ensino tradicional não há uma referência, ou seja, os agrupamentos são diferentes e caracterizam grupos distintos em relação à tabuada de um número. 
Na tabuada do número quatro no sistema de Elkonin-Davydov, quando o multiplicador aumenta em uma unidade, o produto aumentará em quatro unidades, isso é traduzido a partir da propriedade distributiva da multiplicação em relação à adição.

$$
\begin{aligned}
& 4 \times 1=4 \times(0+1)=0+4=4 \\
& 4 \times 2=4 \times(1+1)=4+4=8 \\
& 4 \times 3=4 \times(2+1)=8+4=12
\end{aligned}
$$

Figura 5: Representação da tabuada do número quatro na reta numérica

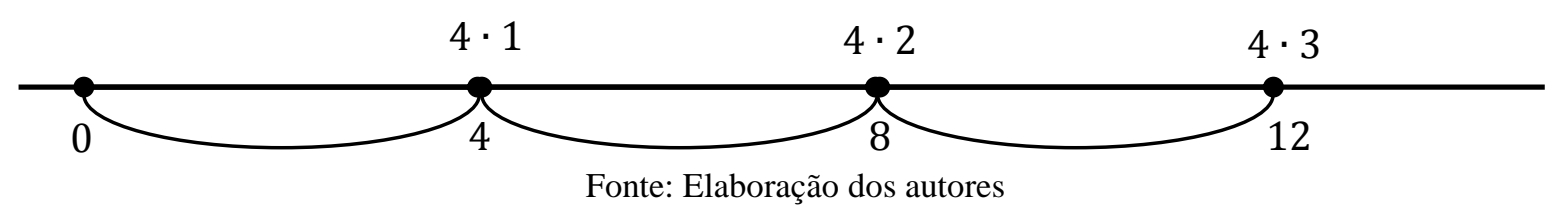

A propriedade distributiva possibilita a memorização da tabuada pela compreensão da essência dos elementos que a caracteriza, ao invés de uma memorização mecânica comum no ensino tradicional.

A partir da discussão na formação, das significações dos elementos conceituais da multiplicação, foi introduzida a divisão. Nesse contexto, retomamos a tarefa sobre a grandeza volume elucidada na multiplicação, mas com outra finalidade. Nessa próxima tarefa é conhecida a medição do volume $\mathrm{C}$ por meio da unidade básica $\mathrm{A}$, porém se desconhece a quantidade de vezes que o volume B cabe em C.

Tarefa2: A partir da representação da medição do volume C, por meio das unidades A e B, obtenha o valor desconhecidocom o auxílio da reta numérica.

Figura 6: Representação dos elementos correspondente a tarefa 2

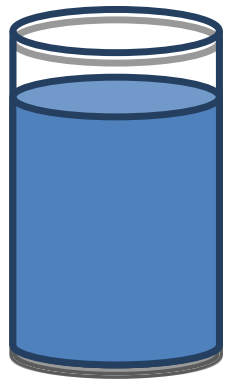

C

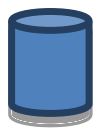

A

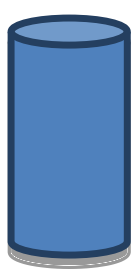

B

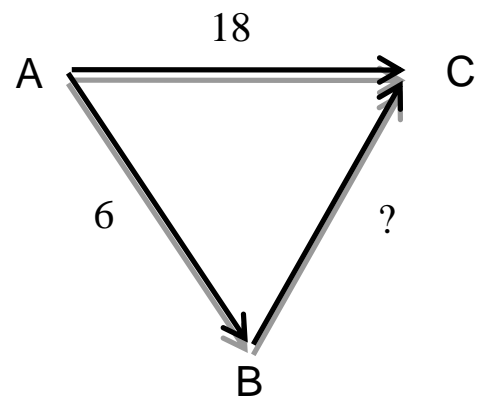

Fonte: material elaborado por Crestani (2016) 
Essa tarefa pressupõe a interpretação dos elementos conceituais na representação objetal e gráfica (esquema). O esquema indica a medida do volume $\mathrm{C}$ com a unidade básica A, bem como, a medida da unidade intermediária B com a unidade A. No entanto, é desconhecida a quantidade de vezes que a unidade B se apresenta no volume $\mathrm{C}$.

A reta numérica (figura 7) auxiliará a identificação do número de vezes que a medida intermediária se repete no volume C. Esse processo de obtenção do valor desconhecido remete ao pensamento da divisão, isto é, saber quantas vezes o número seis está presente no número dezoito $(18 \div 6=3)$.

Figura 7:Desenvolvimento da tarefa 2 na reta numérica

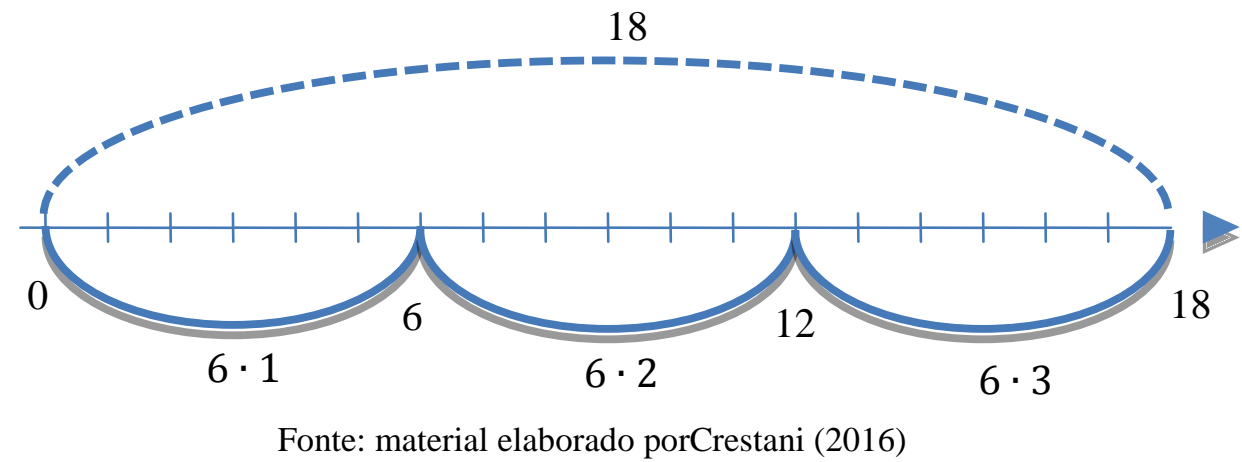

Essa tarefa traz algo diferente em comparação com a multiplicação, isto é, o valor desconhecido. Tal diferença é a quantidade de vezes em que a medida da unidade intermediária se repete no todo - grandeza a ser medida. Enquanto na multiplicação, o valor a ser obtido remete ao tamanho da grandeza que será medida.

No sistema Elkonin-Davydov a divisão envolve agrupamentos na relação entre grandezascom o significado da identificação de quantas vezes uma unidade de medida cabe em outra grandeza. No entanto, antes da formação as professoras compreendiam a divisão com a ideia de "distribuir, separar, repartir". Esse entendimento revela que o aspecto visual predomina no ensino de divisão, isto é, a partir da quantidade de elementos de um conjunto, eles são organizados em grupos com o mesmo número de objetos. Por exemplo, oito dividido para dois significa distribuir elementos para cada um dos dois grupos, de modo que eles tenham quantidades iguais.

Nesse sentido, o significado da divisão consiste nos grupos terem a mesma quantidade de elementos, realçado pelas professoras, remete ao uso da observação direta somente de objetos discretos a partir dos órgãos dos sentidos. Davýdov (1982, p. 307) afirma que "as dependências empíricas podem ser verbalmente descritas como resultados de observações 
sensoriais". Tal manifestação, para esse autor, é indicativa do desenvolvimento do pensamento empírico, nos estudantes, advindo do sistema de ensino tradicional vigente.

No início da formação algumas professoras refletiram que o novo modo de ensinar carece de entendimento, isso se verifica na fala: "eu não penso que o meu aluno não vai aprender, eu penso que a gente não consegue se apropriar desse conceito [divisão] numa qualidade que a gente consiga aplicar na sala de aula". Tal reflexão indica a percepção de algo diferente pela professora no estudo do sistema Elkonin-Davydov e demonstra a relevância desse sistema de ensino, mas requerestudo e aprofundamento, pelas professoras, para a sua implementaçãoem sala de aula.

Isso se confirma, também, na seguinte fala: "eu estou aqui rabiscando, pensando, discutindo com as minhas colegas, mas é difícil a gente aprender, aprender a ensinar". A discussão no coletivo suscita pensar um novo modo de organizar o ensino com as finalidades almejadas (apropriação dos conceitos pelos estudantes), visto que os resultados obtidos pela organização do ensino adotada, ditos pelas próprias professoras, não eram satisfatórios.

No entanto, mudar um modo de pensar consiste em superar a forma vigente e isso demanda ultrapassar os seus obstáculos para atingir a finalidade desejada dessa nova forma de organizar o ensino. O pensar de outromodo está vinculado a uma teoria que corresponde aos anseios das professoras no processo de ensino.

As professoras desejam que os estudantes em anos posteriores relacionem os conceitos apropriados anteriormente. Para isso acontecer estudiosos da Teoria Histórico-Cultural e do Ensino Desenvolvimental propõem a organização do ensino por meio da formação de sistemas conceituais que envolvem a essência desses conceitos, bem como, os seus elos de ligação para que o estudante pense teoricamente.

No Brasil, frequentemente, a multiplicação e a divisão, desde os anos inicias do Ensino Fundamental são ensinadas sem uma relação que fundamenta essas duas operações. Para as professoras isso ocasiona confusão aos estudantes na resolução de situações sobre essas duas operações. Mais especificamente, as professoras afirmam que: "eles se confundem muito, é de dividir ou de vezes" e, além disso, não identificam qual a operação a ser realizada.

No sistema Elkonin-Davydov a relação entre a multiplicação e a divisão está no contexto da medição e é formada por uma grandeza a ser medida e as unidades: básica e intermediária, como abordado anteriormente. Essa diferenciação entre os modos de organização do ensino de multiplicação e divisão fica evidente naseguinte fala da professora: 
"Hoje eu consegui ter uma luz, eu vi que a multiplicação e a divisão estão muito relacionadas, eu acho que assim dá para tentar fazer, eu achei um pouco mais simples isso. Porque ali eu consegui ver (representação na reta numérica) quatro vezes três é igual a doze, doze dividido por quatro é igual a três. Então ali está relacionada à multiplicação e a divisão, acho que isso eu consigo fazer, não sei o resto, o processo todo."destaque nosso.

A formação permitiu que a professora constatasse que a multiplicação e a divisão, no sistema Elkonin-Davydov, possuem os mesmos elementos conceituais articulados em uma relação essencial, ou seja, as unidades: básica e intermediária, bem como, a grandeza a ser medida. Essa fala indica movimento no pensamento da professora em processo de superação do ensino vigente para atingir um novo modo de apropriação.

No ensino brasileiro a multiplicação até é articulada com a divisão, somente para comprovar que o seu resultado está correto. Por exemplo, ao dividir doze por quatro, se busca na tabuada do quatro, o número que multiplicado por ele resulta no doze. Essa compreensão tem por base a tendênciatecnicista que prioriza o resultado em detrimentodo processo. Em outras palavras,se cria um método com procedimentos "regras" para se chegar a um resultado.

Davídov (2019) ao se referir ao conhecimento empírico, diz que é sua característica fazer com que o estudante saiba fazer e não falar sobre o que fez. Isso se traduz no ensino de um conceito matemático que o importante é chegar ao resultado e se exclui o seu processo de desenvolvimento.

Diante das manifestações das professoras sobre o ensino realizado antes da formação, identificamos que a multiplicação e a divisão possuem um teor empírico em suas significações conceituais. Vale lembrar que, esse projeto decorre de problemas de aprendizagem no sexto ano com relação à multiplicação e a divisão. Para isso, se pensou a mudança da organização do ensino no quinto ano. Nesse sentido, vale expressar a seguinte fala de uma professora:

“É mais complicado explicar para o quinto ano esse método do que para o primeiro ano, seria interessante de repente começar desde o primeiro ano porque quando chega no quinto ano eles já estão com aquele, com o básico do básico. Agora mudar no quinto ano é complicado. O ideal é começar com o conceito de número."

Desse modo, ressaltamos que o sistema de Elkonin-Davydov é organizado sobre uma fundamentação geral, na relação entre grandezas que direciona para as singularidades dos conceitos matemáticos.Assim, desde o primeiro ano escolar os elementos conceituais do número realse constituem em base teórica na construção da significação de multiplicidade e divisibilidade em conceitos posteriores. 


\section{CONSIDERAÇÕES FINAIS}

Com base nos encontros realizados no projeto de extensão e no problema de investigação que consistiu em analisar as contribuições de uma formação de professoras dos anos iniciais para reelaborar a organização do ensino de multiplicação ede divisão.Constatamos que estudar o sistema de Elkonin-Davydov com a prioridade na conexão da multiplicação e da divisão a partir de elementos conceituais comuns, mas com uma finalidade distinta, foi primordial para a elaboração dos conceitos. Pois, permitiu que as professoras refletissem sobre o modo fragmentado do ensino dessas operações, característica presente no ensino brasileiro de matemática.

Outra manifestação explícita nas falas das professoras está vinculada aos fundamentos matemáticos em relação ao papel passivo e ativo, respectivamente nessa ordem, dos termos multiplicando e multiplicador. Para as professoras a organização do ensino dos elementos da multiplicação é pautada na expressão verbal, o qual indica papéis inversos aos fundamentos matemáticos.

O ensino de divisão para as professoras era organizado somente relacionado à quantidade discreta que prioriza objetos soltos vinculados a contagem, com o significado de repartir ou distribuir em grupos. Essa forma de ensinar contribui para que essas operações sejam vistas de modo fragmentado, visto que não se estabelece uma conexão com os elementos conceituais da multiplicação.

Em contraposição no sistema Elkonin-Davydov, a multiplicação e a divisão são ensinadas no contexto da medição a partir dos mesmos elementos conceituais, isto é, as unidades: básica e intermediária, bem como, a grandeza a ser medida. A conexão entre essas duas operações é garantida pela unidade intermediária, ou seja, esse elemento é o mesmo na relação entre a unidade básica e a grandeza a ser medida.

Diante da análise inferimos que, a organização do ensino promovida pelas professoras antes do curso de extensão era vinculada ao conhecimento empírico, isto é, as significações aparentes do conceito e as suas relações imediatas que direcionam para o saber fazer sem, na maioria das vezes, entender o porquê fazem. Contudo, os encontros realizados no referido curso de extensão possibilitou às professoras o estudo do sistema Elkonin-Davydov fundamentado em outra concepção, cujo objetivo é o desenvolvimento do pensamento teórico. Esse sistema de ensino propicia, aos estudantes, apropriação das significações 
essenciais do conceito, bem como, o envolvimento de elementos conceituais que se interrelacionam, como já identificado na multiplicação e na divisão.

\section{AGRADECIMENTO E FONTE DE FINANCIAMENTO}

O projeto de extensão que originou esse artigo foi financiado pela Universidade do Extremo Sul Catarinense em colaboração com o setor PROACAD - Diretoria de Extensão, Cultura e Ações Comunitárias. Desse modo, agradecemos essa Universidade por permitir um espaço de formação para professoras da Educação Básica.

\section{REFERENCIAS}

CARAÇA, B. J. Conceitos Fundamentais da Matemática. Lisboa: Gradiva, 2010.

CRESTANI, Sandra. Organização do ensino de matemática na perspectiva do desenvolvimento do pensamento teórico: uma reflexão a partir do conceito de divisão. 2016. 126 f. Dissertação (Mestrado em Educação) - Universidade do Sul de Santa Catarina, Tubarão, 2016.

DAVIDOV, V. V; MÁRKOVA, A. O conceito de atividade de estudo dos estudantes. In: PUENTES, R. V.; CARDOSO, C. G. C. C.; AMORIN, P. A. P. (Org.). Teoria da atividade de estudo: Contribuições de D. B. Elkonin, V. V. Davidov e V. V. Repkin: Livro I. Curitiba: CRV, 2019. p. 191-214.

DAVIDOV, V. V. Atividade de estudo e aprendizagem desenvolvimental. In: PUENTES, R. V.; CARDOSO, C. G. C. C.; AMORIN, P. A. P. (Org.). Teoria da atividade de estudo: Contribuições de D. B. Elkonin, V. V. Davidov e V. V. Repkin: Livro I. Curitiba: CRV, 2019. p. 191-214.

DAVÍDOV, V.V. Análisis de losprincipiosdidácticos de laescuela tradicional y posiblesprincipios de enseñanzaenel futuro próximo. In: SHUARE, M. La psicología Evolutiva y pedagógica enla URSS. Moscú: Progreso, 1987. p. 143-155.

DAVÍDOV, V. La enseñanza escolar y eldesarrollo psíquico: investigación teórica y experimental. Tradução de Marta ShuareMoscú: Editorial Progreso, 1988.

DAVÝDOV, V. V. Tipos de generalizaciónenlaenseñanza. $3^{a}$ edição. Habana: Editorial Pueblo y Educación, 1982.

MOURA, M. O. et al. Atividade orientadora de ensino: unidade entre ensino e aprendizagem. Revista Diálogo Educ., Curitiba, v. 10, n. 29, p. 205-229, jan./abr. 2010. 
ROSA, J. E. Proposições de Davydov para o ensino de matemática no primeiro ano escolar: inter-relações dos sistemas de significações numéricas. 2012. 244 f. Tese (Doutorado em Educação) - Universidade Federal do Paraná, Curitiba, 2012.

SOARES, F. C. C. O ensino desenvolvimental e a aprendizagem de matemática na primeira fase do ensino fundamental. 2007. 118 f. Dissertação (Mestrado em Educação)Universidade Católica de Goiás, Goiânia, 2007. 